\title{
Clinical characteristics and associated factors of trigeminal neuralgia: experience from Addis Ababa, Ethiopia
}

\author{
Biniyam Alemayehu Ayele ${ }^{*}$, Abenet Tafesse Mengesha and Yared Zenebe Zewde(B)
}

\begin{abstract}
Background: Trigeminal neuralgia (TN) is considered one of the most painful illnesses known to medical practice. Little is known about TN in Ethiopia. Our study aimed to assess clinical characteristics, treatment, and associated factors of TN.
\end{abstract}

Method: A cross-sectional study was conducted on a total of 61 patients with confirmed Trigeminal neuralgia visiting outpatient neurology clinics of two government teaching Hospitals and two private health facilities in Addis Ababa, Ethiopia between June 2019 and March 2020.

Results: Our participants' age range between 21 and 78 years with mean \pm SD age of $50.7 \pm 14.2$ years. Males accounted for $50.8 \%$. Twenty-five (41\%) reported a prior history of one or more tooth extraction on the painful side. In the majority (68.9\%) of the patient's right side of the face was affected. The mandibular nerve was the commonly involved branch (47.5\%). Fifty-five (90.2\%) of patients fulfilled criteria for classical TN and 9.8\% had symptomatic TN. The majority of the participants reported mixed types of pain such as burning, lancinating, and electric shock-like. Well defined trigger zone was identified in one-third (36\%) of cases. Carbamazepine was the most commonly prescribed drug with a median dose of $600 \mathrm{mg}$ (IQR: 400 - $1000 \mathrm{mg}$ ). Two-third of the patients reported prominent satisfaction. The mean ( \pm SD) dose of carbamazepine used to control the pain was significantly higher among those with dental extraction history as compared to those with no history of dental extraction $(736 \pm 478.6 \mathrm{mg} V \mathrm{~s}$ $661.1 \pm 360.4 \mathrm{mg}$, respectively, $\mathrm{T}=-2.06, p=0.0495 \% \mathrm{Cl}:-213.41$ to -2.98$)$. A statistically significant number of patients who had single branch involvement reported prominent satisfaction with their treatment as compared to those who had more than one branch involvement. (95\% Cl: 1.3-3.8: $p=0.006)$.

Conclusion: The majority of our patients had Classical TN in the mandibular nerve distribution on the right side of the face and well satisfied with carbamazepine only treatment. Furthermore, we observed a higher proportion of dental extraction among our patients, hinting at the scale of miss and delayed-diagnoses. Thus, we recommend conducting a well-designed prospective study to support our findings.

Keywords: Trigeminal neuralgia, Classical TN, Symptomatic TN, Tooth extraction, Carbamazepine

\footnotetext{
*Correspondence: biniyam.alemayehu@aau.edu.et; biniyam.a7@gmail.com Department of Neurology, School of Medicine College of Health Sciences, Addis Ababa University, PO Box 6396, Liberia Street, Lideta sub-city, Addis Ababa, Ethiopia
}

C C The Author(s). 2020 Open Access This article is licensed under a Creative Commons Attribution 4.0 International License, which permits use, sharing, adaptation, distribution and reproduction in any medium or format, as long as you give appropriate credit to the original author(s) and the source, provide a link to the Creative Commons licence, and indicate if changes were made. The images or other third party material in this article are included in the article's Creative Commons licence, unless indicated otherwise in a credit line to the material. If material is not included in the article's Creative Commons licence and your intended use is not permitted by statutory regulation or exceeds the permitted use, you will need to obtain permission directly from the copyright holder. To view a copy of this licence, visit http://creativecommons.org/licenses/by/4.0/ The Creative Commons Public Domain Dedication waiver (http://creativecommons.org/publicdomain/zero/1.0/) applies to the data made available in this article, unless otherwise stated in a credit line to the data. 


\section{Background}

Trigeminal neuralgia (TN) is a relatively rare neuropathic disorder, characterized by extremely painful episodic facial pain involving one or more trigeminal nerve branches. Based on the International Classification of Headache Disorders- 3rd Edition (ICHD-3) TN is classified into three: Classical TN, Secondary TN, and Idiopathic TN, based on the presence or absence of an apparent disease process that could explain the neuralgia [1]. Considering the wide variation in its clinical symptomatology, delayed or misdiagnosis is common. It is not uncommon for patients with Trigeminal neuralgia to be managed by non-neurologist health professionals such as dentists, general practitioners, internists, anesthesiologists, and neurosurgeons [2].

Quality of pain related to $\mathrm{TN}$ is described as electric shock-like, sharp, stabbing, or shooting, often triggered by immaterial sensory input such as washing face, brushing, wind blow, and talking [3]. The exact pathophysiology of TN is still largely uncharted. However, current consensus regarding the underlying etiology of TN orbits around focal demyelination of trigeminal nerve root entry zone as a result of compression by an aberrant loop of artery or vein often referred to as Classical TN (CTN). Furthermore, it has been demonstrated that TN is more common in patients with multiple sclerosis, which is often resulted in Symptomatic or Secondary TN (STN). Few published reports support the possible inheritance pattern of Trigeminal neuralgia, supporting the role of genetics as etiology of TN. Familial classic trigeminal neuralgia (FCTN), may account for $2 \%$ of cases of TN [4].

The variabilities related to clinical features of trigeminal neuralgia may be attributable to environmental and genetic influences. Information on the clinical pattern, treatment responses, and associated factors of $\mathrm{TN}$ are rare in the African continent, especially in Sub-Saharan Africa (SSA) countries [5]. To the author's knowledge, so far there is no published data from Ethiopia regarding TN. Therefore, the objective of this study was to determine the clinical characteristics, treatment, and associated factors of Trigeminal neuralgia patients attending tertiary level government Hospitals and private health facilities in Addis Ababa, Ethiopia. Likewise, finding from this observation will contribute to the existing understanding regarding Trigeminal neuralgia, as data from Sub-Saharan Africa was lacking regarding TN.

\section{Methods}

\section{Study objective and study setting}

Our study aimed to assess clinical characteristics, treatment, and associated factors of TN. The study was conducted at the outpatient neurology clinics of two government teaching hospitals (Tikur Anbessa Specialized
Hospital (TASH) and Zewditu Memorial Hospital (ZMH) and two private health facilities (Bethezata General Hospital and Yehuleshet Specialty Clinic) in Addis Ababa, Ethiopia.

\section{Study period and design}

A cross-sectional, observational study was conducted between June 2019 and March 2020. All 61 patients who were age $>18$ years, having a clinical diagnosis of TN as per the International Classification of Headache Disorders-3rd Edition (ICHD-3) criteria [1] and consented to participate were included. Treatment satisfaction was assessed in three categories, no satisfaction, mild satisfaction, prominent (moderate + significant) satisfaction [6, 7] (Table 1).

\section{Data collection tool and procedure}

A semi-structured questionnaire (Supplementary file 1) assessing the socio-demographic, clinical characteristics, treatment type and dose, and treatment satisfaction level were administered to each participant by three board certified neurologists. Patients Electronic Medical Record (EMR) was also reviewed for additional clinical data.

\section{Data analysis}

Completed questionnaires were cleaned and entered into Statistical Package for Social Sciences (SPSS) Version 25 for analysis. We used descriptive statistics with frequency and proportion for categorical data and mean, median, interquartile range (IQR), range, and standard deviation (SD) for continuous variables. Associations between selected variables were tested using Student's ttest and Fisher's exact or Chi-square tests. Results were interpreted and presented using appropriate tables and figures. Variables with $p$ values $<0.05$ were considered statistically significant.

Table 1 Trigeminal neuralgia diagnostic criteria based on ICHD3

A. Recurrent paroxysms of unilateral facial pain in the distribution(s) of one or more divisions of the trigeminal nerve, with no radiation beyond, and fulfilling criteria $\mathbf{B}$ and $\mathbf{C}$.

B. Pain has all of the following characteristics:

1. Lasting from a fraction of a second to two minutes

2. Severe intensity

3. Electric shock-like, shooting, stabbing or sharp in quality

C. Precipitated by innocuous stimuli within the affected trigeminal distribution

D. Not better accounted for by another ICHD-3 diagnosis

ICHD-3: International Classification of Headache Disorders-3rd Edition criteria 


\section{Results}

Demographics, duration of illness, dental extraction, anatomy, and sensory abnormalities

A total of 61 patients with Trigeminal neuralgia who visited four health facilities over nine months were included in this study. The mean $\pm \mathrm{SD}$ age of the study participants was $50.7 \pm 14.2$ years (Range: $21-78$ years). Males accounted for $50.8 \%$. The mean \pm SD of for disease duration was $5.7 \pm 3.9$ years.

Twenty-five $(41 \%)$ of the patients reported removal or filling of one or more lower molar/ premolar tooth. In two-third (68.9\%) of the patient's right side of the face was affected, $29.5 \%$ left side was affected, at the same time, the bilateral face was involved in $1.6 \%$. In half of the patients, the mandibular branch (V3) was involved, followed by the involvement of both maxillary and mandibular branch $(\mathrm{V} 2+\mathrm{V} 3)$ in $34.4 \%$ of the patients. No patient demonstrated the involvement of an isolated ophthalmic branch (V1). Half of the patients had a diagnosis of TN for $<5$ years, while $11.5 \%$ of them were living with $\mathrm{TN}$ for more than 10 years. One patient (1.6\%) had ipsilateral facial sensory abnormality (Table 2).

Table 2 Demographics, duration of illness, tooth extraction, anatomy, and sensory abnormality

\begin{tabular}{|c|c|c|}
\hline Characteristics & Frequency (N) & Percent (\%) \\
\hline \multicolumn{3}{|l|}{ Age category } \\
\hline $21-40$ years & 18 & 29.5 \\
\hline $41-60$ years & 26 & 42.6 \\
\hline$>60$ years & 17 & 27.9 \\
\hline \multicolumn{3}{|l|}{ Gender } \\
\hline Male & 31 & 50.8 \\
\hline Female & 30 & 49.2 \\
\hline \multicolumn{3}{|c|}{ Duration of illness } \\
\hline$<5$ years & 31 & 50.8 \\
\hline $5-10$ years & 23 & 37.7 \\
\hline$>10$ years & 7 & 11.5 \\
\hline \multicolumn{3}{|l|}{ Dental extraction } \\
\hline Yes & 25 & 41 \\
\hline No & 36 & 59 \\
\hline \multicolumn{3}{|c|}{ Side of the face affected } \\
\hline Right sided & 42 & 68.9 \\
\hline Left sided & 18 & 29.5 \\
\hline Bilateral & 1 & 1.6 \\
\hline \multicolumn{3}{|c|}{ Trigeminal nerve branches } \\
\hline V2 & 6 & 9.8 \\
\hline V3 & 29 & 47.5 \\
\hline$V_{2}+V_{3}$ & 21 & 34.4 \\
\hline$V_{1}+V_{2}+V_{3}$ & 5 & 8.2 \\
\hline
\end{tabular}

$\mathrm{V}_{1}$ : Ophthalmic branch, $\mathrm{V}_{2}$ : Maxillary branch, and $\mathrm{V}_{3}$ : Mandibular branch
Classification, pain characteristics, autonomic symptoms, and pain during sleep

Fifty-five (90.2\%) of our study participants fulfilled the criteria of Classical/Idiopathic TN (CTN/ITN), while 9.8\% had Symptomatic TN (STN) secondary to CPA meningioma, brainstem cavernoma, and Multiple sclerosis. The average age of patients with CTN/ ITN (51.5 \pm 14 years) was higher compared to patients with STN $(45.3 \pm 14.7$ years). Out of six patients with diagnoses of STN, 83.3\% were age below 60 years. However, no statistically significant agreement was observed between the age category and classification of TN (Table 3). Most of the participants $(26.2 \%)$ reported mixed quality of pain such as burning, lancinating, and electric shock. Twentytwo (36\%) of them reported having a trigger zone. Among these, the ipsilateral angle of mouth accounted for $21.3 \%$, nasolabial fold accounted for $8.2 \%$, while lower mandibular edge and lower gum accounted for 4.9 and $1.6 \%$, respectively. The majority of the patients reported mixed symptoms such as cold wind blowing, chewing, drinking cold or hot drinks, and having or touching triggering the pain (Table 4$)$. Three $(4.9 \%)$ reported the pain was associated with autonomic symptoms, while $16.4 \%$ reported their pain occasionally wakes them up from sleep. Among the total of 61 study participants, fifteen $(24.6 \%)$ reported their pain to worsen during cold and rainy seasons.

Treatments, treatment satisfaction, and family history Carbamazepine was the commonest prescribed drug among the participants. Forty-one $(67.2 \%)$ of the patients were on Carbamazepine alone, while 11.5, 9.8, 6.6\% were on Carbamazepine + NSAIDs, Carbamazepine + Amitriptyline, and Carbamazepine + Gabapentin, respectively. Few patients were shifted to non-Carbamazepine drugs because of Carbamazepine-induced adverse effects. The median carbamazepine dose of the study participants was $600 \mathrm{mg}$ (IQR: $400-1000 \mathrm{mg}$, range: 0 $2000 \mathrm{mg})$. Forty-two (68.8\%) of study participants reported having prominent satisfaction with pain medication, while $31.1 \%$ reported mild to no satisfaction with their treatment. There is no statistically significant association between treatment regimen and satisfaction ( $p=$ 0.52). Majority of patients on carbamazepine monotherapy reported prominent satisfaction compared to those patients on combination therapies (Fig. 1). Among a total of 61 patients $1.6 \%$ reported a positive family history of TN.

\section{Association between carbamazepine doses and tooth extraction}

We hypothesized that; among our study participants those patients who had a positive history of tooth extraction will require higher doses of carbamazepine 
Table 3 Association between classification of Trigeminal neuralgia and different age category

\begin{tabular}{llll}
\hline & Age Category & & $>$ > 60 years \\
\cline { 2 - 4 } 20-40 years & $41-60$ years & Frequency (\%) \\
\hline Classification of TN & Frequency (\%) & Frequency (\%) & $16(26.2)$ \\
Classical TN & $15(24.6)$ & $24(39.3)$ & $1(1.6)$ \\
Symptomatic TN & $3(4.9)$ & $2(3.3)$ & $17(27.9 \%)$ \\
Total & $18(29.5)$ & $26(42.6)$ & 17 \\
\hline
\end{tabular}

$T N$ Trigeminal neuralgia

compared to those with no history of tooth extraction to relieve their facial pain. On student t-test analysis, we observed statistically significant association between higher doses of carbamazepine $(\mathrm{CBZ}=800 \mathrm{mg})$ and history of tooth extraction $(t=-2.06, p=0.04,95 \%$ CI:-213.41 to 2.98) (Fig. 1). Females patients who had history of dental extraction tend to be on higher doses of carbamazepine compared to their male counter parts. In contrary, no carbamazepine dose difference was observed among males and females with no history of dental extraction (Fig. 2).
Association between treatment satisfaction level and gender, branch involved, and tooth extraction

We performed Pearson's Chi-square test or Fisher exact test to see the association between treatment satisfaction (mild to no satisfaction \& prominent satisfaction) and different categorical variables such as gender, branch of the trigeminal nerve (single or multiple branches) and history of tooth extraction. Those patients having a single branch of trigeminal nerve (V2 or V3) involvement reported prominent satisfaction with their treatment as

Table 4 Classification, pain characteristics, autonomic symptoms, and pain during sleep

\begin{tabular}{|c|c|c|}
\hline Characteristics & Frequency (Yes) & Percent (\%) \\
\hline \multicolumn{3}{|l|}{ Quality of pain } \\
\hline Feeling of being injected with red hot needle & 13 & 21.3 \\
\hline Burning & 10 & 16.4 \\
\hline Lancinating pain & 15 & 24.6 \\
\hline Electric shock like & 7 & 11.5 \\
\hline Mixed features & 16 & 26.2 \\
\hline Total & 61 & 100 \\
\hline \multicolumn{3}{|l|}{ Triggering zone } \\
\hline Ipsilateral angle of mouth & 13 & 21.3 \\
\hline Ipsilateral nasolabial fold & 5 & 8.2 \\
\hline Ipsilateral lower mandibular edge & 3 & 4.9 \\
\hline Ipsilateral lower gum & 1 & 1.6 \\
\hline Total & 22 & 36 \\
\hline \multicolumn{3}{|l|}{ Triggering factors } \\
\hline Mixed triggering factors & 37 & 60.6 \\
\hline Cold wind blowing & 4 & 6.6 \\
\hline Chewing & 5 & 8.2 \\
\hline Drinking cold or hot drinks & 3 & 4.9 \\
\hline Shaving or touching & 4 & 6.6 \\
\hline Non-specific & 8 & 13.1 \\
\hline Total & 61 & 100 \\
\hline \multicolumn{3}{|l|}{ Classification of Trigeminal neuralgia } \\
\hline Classical TN & 55 & 90.2 \\
\hline Secondary TN & 6 & 9.8 \\
\hline Total & 61 & 100 \\
\hline
\end{tabular}

TN Trigeminal neuralgia 


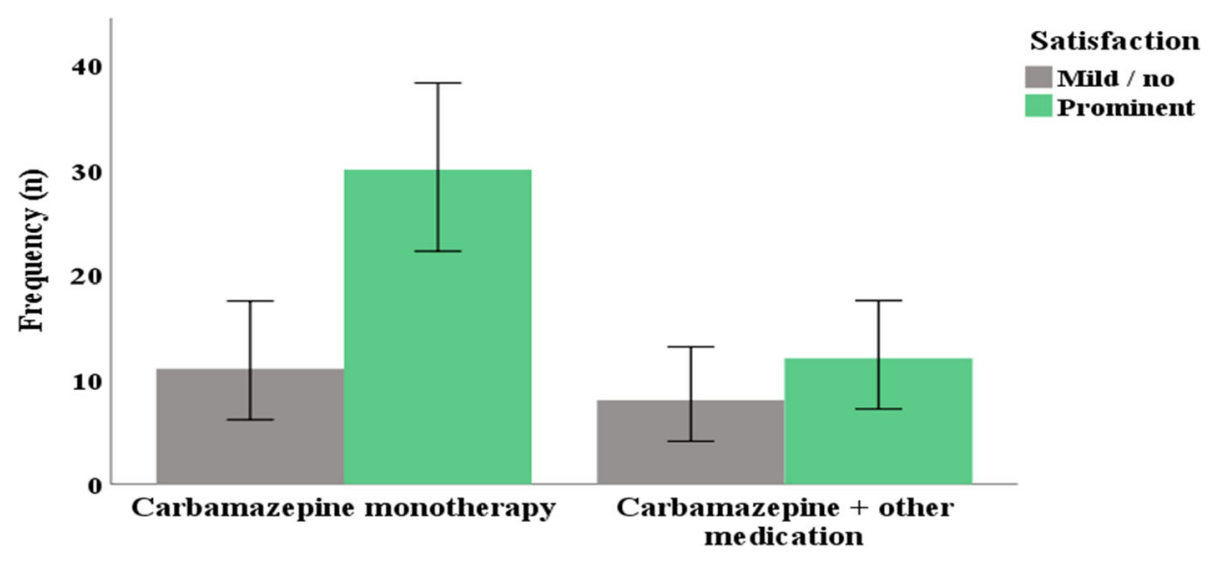

Fig. 1 Bar graph showing association between treatment satisfaction and carbamazepine monotherapy or carbamazepine combination with other drugs

compared to those with multiple branch involvement $(p=0.006,95 \%$ CI: $1.3-3.8)$. Gender and history of tooth extraction did not show statistically significant agreement with treatment satisfaction with $p=0.7$ and $p=$ 0.6 , respectively (Table 5).

\section{Discussion}

The mean age of our study participants, the proportion of Classical TN to Symptomatic TN, predominant right side involvement were consistent with regional and global figures $[2,8,9]$ Trigeminal neuralgia most often affects females compared to male [2]. However, our study showed slight male predominance $(50.8 \%)$, this is consistent with the regional report $[5,10]$. This difference could be explained with the fact that males tend to seek more medical attention for their illnesses as compared to females in Sub-Saharan countries [5, 9, 10]. Symptomatic TN was commonly seen among younger patients, this is consistent with previous reports $[9,11]$. A higher proportion of our patients had a history of dental extraction, a sign of initial visit to the dental physician before the diagnosis of Trigeminal neuralgia was made. This finding is similar to report from Thailand [8] where $40.5 \%$ reported a history of tooth extraction. The mandibular nerve was the commonest branch to be affected, followed by a mixed mandibular + maxillary branch, while the ophthalmic branch was not involved in any of our study participants, which is in line with previous reports $[12,13]$.

The diagnosis of TN is established based on its characteristic clinical symptoms and investigations are only recommended in atypical presentations. While some of

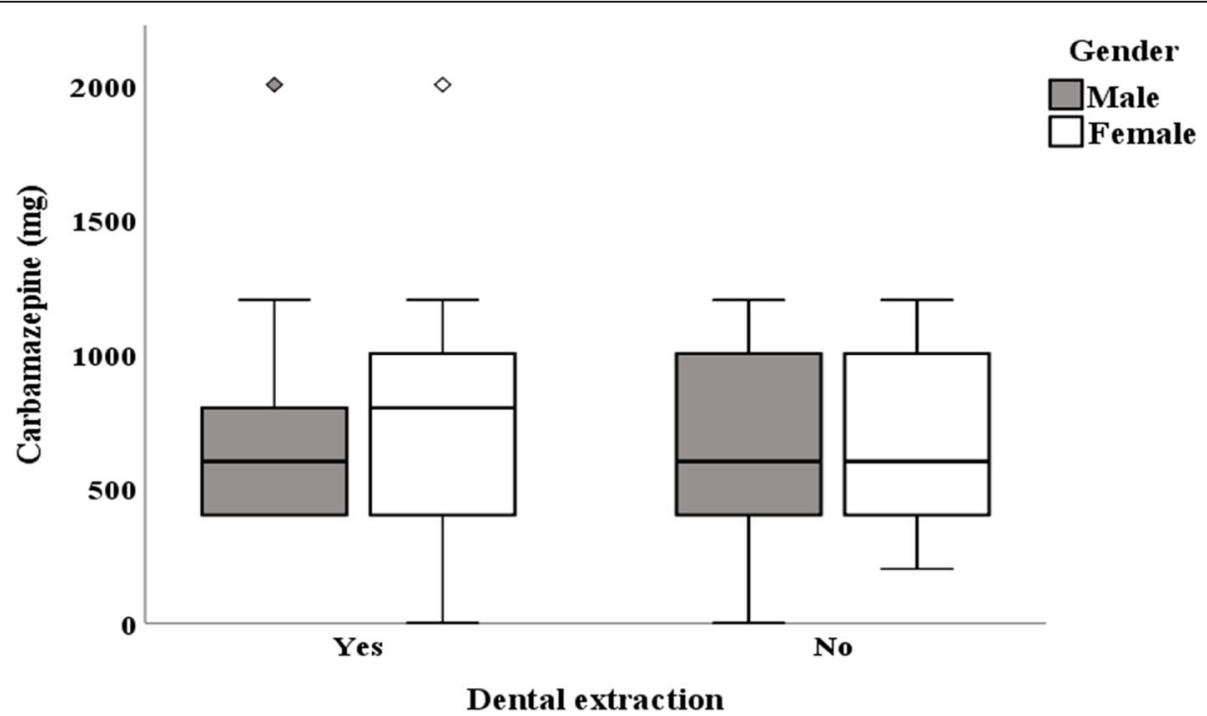

Fig. 2 Box and whiskers plot showing gender distribution of mean carbamazepine dose among individuals having history of dental extraction or not 
Table 5 Association between treatment satisfaction and gender, branch involved, and tooth extraction

\begin{tabular}{|c|c|c|c|c|}
\hline & \multicolumn{2}{|l|}{ Treatment satisfaction } & \multirow{3}{*}{$\begin{array}{l}X^{2}-\text { test } \\
{[95 \% \mathrm{Cl}]}\end{array}$} & \multirow{3}{*}{$\begin{array}{l}P \\
\text { value }\end{array}$} \\
\hline & Mild/No satisfaction & Prominent satisfaction & & \\
\hline & Frequency (\%) & Frequency (\%) & & \\
\hline \multicolumn{5}{|l|}{ Gender } \\
\hline Male & $9(29)$ & $22(71)$ & 1 & 0.7 \\
\hline Female & $10(33.3)$ & $20(66.7)$ & $1.1[0.6-1.8]$ & \\
\hline \multicolumn{5}{|l|}{ Branch Involved } \\
\hline Single branch & $6(31.6)$ & $29(69)$ & $2.2[1.3-3.8]$ & 0.006 \\
\hline Multiple branch & $13(68.4)$ & $13(31)$ & 1 & \\
\hline \multicolumn{5}{|l|}{ Dental extraction } \\
\hline Yes & $7(28)$ & $18(72)$ & $0.8[0.4-1.7]$ & 0.6 \\
\hline No & $12(33.3)$ & $24(66.7)$ & 1 & \\
\hline
\end{tabular}

our participants primarily characterized their pain as "lancinating", "feeling of being injected with a red hot needle", "burning" and "electric shock-like" in descending order, most (26.2\%) described it in mixed terms. A similar study from Thailand reported, mixed pain quality in $22.3 \%$ of $\mathrm{TN}$ patients, although the majority of their patients described it as sharp pain and stabbing/lancinating pain [8] The discrepancies in pain characterization could be explained by patients experience and response to an open or closed question which may lead the patient to one specific answer. All of our participants had some form of pain triggering stimuli and multiple factors were attributed by the majority while no specific factor identified in $13.1 \%$. Clear pain triggering zone was identified in only one-third of the patients. These areas include angles of the mouth, nasolabial fold, lower mandibular edge, and lower gum on the painful side. A study from Thailand also showed among the 188 TN patient's majority reacted to multiple types of stimulus and the most common trigger was chewing [8]. These findings were consistent with reports from Italy, which showed trigger zones were predominantly found around the perioral and nasal region; the authors also recommended utilizing triggers as an essential diagnostic feature of trigeminal neuralgia [14].

Carbamazepine was the most commonly prescribed drug as initial treatment, while a quarter of the patients required the addition of another drug. Two patients were shifted to another drug because of carbamazepine induced adverse reaction [15] Gabapentin, clonazepam, and amitriptyline were also prescribed to those not tolerating carbamazepine $[14,16]$. Patients on carbamazepine reported prominent treatment satisfaction [8]. The mean carbamazepine dose of the study participants was $691.8 \mathrm{mg}$, which is consistent with similar reports [2, 9, $10]$. We found that those patients who had history tooth extraction required a higher dose of carbamazepine compared to those without a history of tooth extraction.
These findings are indicative of the potential diagnoses delay and suboptimal treatment of patients with TN experience in Ethiopia. This is parallel to previous reports showing a significant proportion of patients with TN initially visit non-neurologist health professionals $[2,5]$.

Symptomatic TN was commonly observed among younger patients. Similarly, two-thirds of patients with Classical $\mathrm{TN}$ are the age below 60 years. These findings were consistent with regional reports $[9,11]$. One $(1.6 \%)$ of our study participants reported a family history of Trigeminal neuralgia. This finding was supported by a cluster of familial classic trigeminal neuralgia reported from Spain [4]. Individuals with the involvement of a single branch of trigeminal nerve were associated with prominent treatment satisfaction compared to patients with multiple branch involvement. However, no significant agreement was observed between treatment satisfaction and gender and history of tooth extraction, which could be attributable to the small sample size. A small proportion of our patients reported associated autonomic symptoms during episodic pain, which in line with a recently published prospective study on 158 patients with TN [17]. A limitation of our study includes small sample size few patients investigated with MRI and absence of high-resolution brain MRI which can detect contact between vessel and nerve root, no electrophysiology study was performed, and failed to utilize validated treatment satisfaction scale.

\section{Conclusion}

Our findings suggest the majority of our patients had Classical TN and satisfied well with carbamazepine alone treatment. However, a quarter of them required the addition of the second drug. Furthermore, we observed a higher proportion of dental extraction among our patients, hinting at the scale of miss-diagnoses and delayed diagnoses. Thus, we recommend conducting well designed a larger prospective study to support our findings. 


\section{Supplementary information}

Supplementary information accompanies this paper at https://doi.org/10. 1186/s12903-020-01227-y.

Additional file 1. Study questionnaire, semi-structured questionnaire prepared in order to extract the following data: socio-demographic, clinical characteristics, treatment type and dose, and treatment satisfaction.

\section{Abbreviations}

ICDH-3: International Classification of Headache Disorders-3rd Edition; STN: Symptomatic/Secondary Trigeminal Neuralgia; NSAIDs: Non-steroid antiinflammatory drugs; FCTN: Familiar Classic Trigeminal Neuralgia; ITN: Idiopathic Trigeminal Neuralgia; CTN: Classic Trigeminal Neuralgia; CHS: College of Health Science; AAU: Addis Ababa University; TN: Trigeminal neuralgia

\section{Acknowledgments}

We are thankful to the Department of Neurology, CHS AAU, and Sr. Wubit Bekele, Neurology Head nurse for unreserved support. Finally, we would like to thank all the patients who participated in the study.

\section{Authors' contributions}

BAA, ATM, and YZZ has participated in designing of the study concept, data collection, analytical data analysis, and interpretation, and wrote the manuscript.

\section{Authors' information}

Biniyam A. Ayele, MD is an Assistant Professor of Neurology at the Department of Neurology, CHS AAU. He is actively involved in clinical and research practice in the area of clinical neurology and he has published different articles in areas of headache and pain medicine.

Abenet T. Mengesha, MD, MSc is an Associate Professor of Neurology at the Department of Neurology, CHA AAU. He is a senior clinician and researcher and published multiple articles in areas of clinical neurology.

Yared Z. Zewde is an Assistant Professor of Neurology at the Department of Neurology, CHS AAU. He is actively engaged in clinical and research practice in clinical neurology and he has published different articles in areas of headache and pain medicine.

\section{Funding}

No funding was received from any organization or individuals.

\section{Availability of data and materials}

All data sets on which the conclusions of this manuscript rely are available as spread excel sheet documents and available from the corresponding author on reasonable request.

\section{Ethics approval and consent to participate}

The study received ethical approval from the Institutional Review Board (IRB) at the College of Health Sciences Addis Ababa University (Protocol No. 043/ 19/Neuro). All subjects provided written consent before conducting the interview.

\section{Consent for publication}

Not applicable.

\section{Competing interests}

The authors declare they have no actual or potential competing financial interests.

Received: 18 June 2020 Accepted: 23 August 2020

Published online: 03 September 2020

\section{References}

1. Olesen J, Bes A, Kunkel R, Lance JW, Nappi G, Pfaffenrath V, et al. The International Classification of Headache Disorders. Cephalalgia. 2013;33:629_ 808.

2. Bendtsen L, Zakrzewska JM, Abbott J, Braschinsky M, Di Stefano G, Donnet A, et al. European Academy of Neurology guideline on trigeminal neuralgia. Eur J Neurol. 2019;26:831-49.
3. Montano N, Conforti G, Di Bonaventura R, Meglio M, Fernandez E, Papacci F. Advances in diagnosis and treatment of trigeminal neuralgia. Ther Clin Risk Manag. 2015;11:289-99.

4. Fernández Rodríguez B, Simonet C, Cerdán DM, Morollón N, Guerrero P, Tabernero C, et al. Familial classic trigeminal neuralgia. Neurol. 2019;34:22933.

5. Adeniyi O, Owotade FJ. Patterns of Presentation of Trigeminal Neuralgia in Patients Attending the Oral Medicine Clinic in A Nigerian Tertiary Hospital; 2018. p. 325430461.

6. Demir MC, Hazim O, Celik Y.Determining the Level of Job Satisfaction of Nurses Working at Turkish Military Hospital. Military Medicine. 2002;167:4025.

7. Xesfingi S, Vozikis A. Patient satisfaction with the healthcare system: assessing the impact of socio- economic and healthcare provision factors. BMC Health Serv Res. 2016:16(94):1-7.

8. Jainkittivong A, Aneksuk V, Langlais RP. Trigeminal neuralgia: a retrospective study of 188 Thai cases. Gerodontology. 2012;29:e611-7.

9. Omoregie $\mathrm{O}, \mathrm{Okoh} \mathrm{M}$. Early response to medical treatment of trigeminal neuralgia in a Nigerian population. Niger Med J. 2015;56:381.

10. Obermann M. Treatment options in trigeminal neuralgia. Ther Adv. Neurol Disord. 2010;3(2):107-15

11. Bahgat D, Ray DK, Raslan AM, McCartney S, Burchiel KJ. Trigeminal neuralgia in young adults. J Neurosurg. 2011;114:1306-11.

12. Majeed MH, Arooj S, Khokhar MA, Mirza T, Ali AA, Bajwa ZH. Trigeminal Neuralgia: A Clinical Review for the General Physician. Cureus. 2018;10(12): e3750.

13. Maarbjerg S, Di Stefano G, Bendtsen L, Cruccu G. Trigeminal neuralgia Diagnosis and treatment. Cephalalgia. 2017;37(7):648-57.

14. Di Stefano G, Maarbjerg S, Nurmikko T, Truini A, Cruccu G. Triggering trigeminal neuralgia. Cephalalgia. 2018;38:1049-56.

15. Garg P, Pahuja M, Nagarth H, Singh S, Kanwaljeet Kaur R, Aggarwal K, et al Trigeminal Neuralgia Trigeminal Neuralgia: Etiopathogenesis, Diagnostic criteria and Treatment Modalities-A Review. J Adv Med Dent Sci. 2013;1(2): 106-11.

16. Gulur P, Wainger BJ, Young A. Head and Facial Trigeminal Neuralgia. Physical medicine and rehabilitation. 2015.

17. Maarbjerg S, Gozalov A, Olesen J, Bendtsen L. Trigeminal neuralgia-a prospective systematic study of clinical characteristics in 158 patients. Headache. 2014;54:1574-82.

\section{Publisher's Note}

Springer Nature remains neutral with regard to jurisdictional claims in published maps and institutional affiliations.

Ready to submit your research? Choose BMC and benefit from:

- fast, convenient online submission

- thorough peer review by experienced researchers in your field

- rapid publication on acceptance

- support for research data, including large and complex data types

- gold Open Access which fosters wider collaboration and increased citations

- maximum visibility for your research: over $100 \mathrm{M}$ website views per year

At $\mathrm{BMC}$, research is always in progress.

Learn more biomedcentral.com/submission 